\title{
Prevalence of tick-borne haemoparasites in small ruminants in Turkey and diagnostic sensitivity of single-PCR and RLB
}

Huseyin Bilgin Bilgic ${ }^{*}$, Serkan Bakırcl', Onur Kose ${ }^{1}$, Ahmet Hakan Unlu², Selin Hacılarlıoglu, Hasan Eren ${ }^{1}$, William Weir ${ }^{3}$ and Tulin Karagenc ${ }^{1}$

\begin{abstract}
Background: Tick-borne haemoparasitic diseases (TBHDs), caused by Theileria, Babesia, Anaplasma and Ehrlichia, are common in regions of the world where the distributions of host, pathogen and vector overlap. Many of these diseases threaten livestock production and some also represent a concern to human public health. The primary aim of this study was to determine the prevalence of the above-mentioned pathogens in a large number of blood samples $(n=1979)$ collected from sheep $(n=1727)$ and goats $(n=252)$ in Turkey. A secondary aim was to assess the diagnostic sensitivity of a number of species-specific polymerase chain reaction (PCR) tests and the reverse line blotting (RLB) assay. DNA samples were screened using species-specific PCR for the presence of Theileria ovis, Theileria sp. MK, T. lestoquardi, T. uilenbergi, T. Iuwenshuni, Babesia ovis, Anaplasma ovis and A. phagocytophilum while RLB was undertaken to test for the presence of all known Theileria, Babesia, Anaplasma and Ehrlichia species. The diagnostic sensitivity of these two approaches was then compared in terms of their ability to detect single species and mixed infections.
\end{abstract}

Results: Overall, 84 and $74.43 \%$ of the small ruminants sampled were identified as hosting one or more pathogen(s) by species-specific PCR and RLB respectively. The presence of Theileria sp. OT1, T. luwenshuni and T. uilenbergi in Turkey was revealed for the first time while the presence of Babesia motasi, B. crassa and T. separata in Turkish small ruminants was confirmed using molecular methods. A high prevalence of mixed infection was evident, with PCR and RLB approaches indicating that 52.24 and $35.42 \%$ of animals were co-infected with multiple species, respectively. More than $80 \%$ of the mixed infections contained T. ovis and/or A. ovis. The RLB approach was found to be capable of detecting mixed infections with species such as Theileria sp. OT1, Theileria sp. OT3,T. separata, B. crassa and Babesia spp.

Conclusion: The results indicated that pathogens causing TBHDs are highly prevalent in sheep and goats in Turkey. The diagnostic sensitivity of species-specific single PCR was generally higher than that of RLB. However, the latter approach was still capable of identifying a high proportion of individuals containing mixed-species infections. The use of species-specific single PCR is recommended to accurately estimate pathogen prevalence and to identify co-infected hosts.

Keywords: Prevalence, Tick-borne pathogens, Sheep, Goat, RLB, Species-specific PCR, Turkey

\footnotetext{
*Correspondence: hbilgic@adu.edu.tr

'Department of Parasitology, University of Adnan Menderes, Faculty of

Veterinary Medicine, 09016 Isıkl/Aydın, Turkey

Full list of author information is available at the end of the article
} 


\section{Background}

Tick-borne haemoparasitic diseases (TBHDs) caused by protozoans (Theileria, Babesia) and bacteria (Anaplasma) Ehrlichia) impose a serious constraint upon livestock health and production in tropical and sub-tropical regions where the distributions of host, pathogen and vector overlap [1]. Over the past decade, much of the focus of TBHD research of livestock has been directed toward bovine pathogens and small ruminants have received limited consideration [2]. However, due to a growing appreciation of the socio-economic importance of small ruminants, more attention is now being directed toward pathogens of sheep and goats [2].

Haemoparasites observed in sheep and goats include Theileria ovis, Theileria separata, Theileria sp. OT1, Theileria sp. OT3, Theileria sp. MK, Theileria lestoquardi (formerly T. hirci), Theileria luwenshuni (Theileria sp. China 1), Theileria uilenbergi (Theileria sp. China 2), Babesia ovis, Babesia motasi, Babesia crassa [3-7] and Anaplasma ovis, Anaplasma phagocytophilum, Ehrlichia ruminantium, Ehrlichia ovina and Ehrlichia sp. Omatjenne [8-10]. Babesia ovis, B. motasi, A. phagocytophilum, T. lestoquardi, T. luwenshuni and T. uilenbergi are considered to be pathogenic, while T. ovis, T. separata and $B$. crassa are considered to be non-pathogenic in sheep and goats. No conclusive evidence yet exists about the pathogenicity of recently-described species such as Theileria sp. OT1, Theileria sp. OT3 and Theileria sp. MK [2, 5, 7, 9-14].

Losses attributed to TBHDs include mortality, production losses, veterinary diagnosis/treatment costs and tick control [15]. In small ruminants, TBHDs often manifest as sub-clinical infections. In animals that survive acute disease, a long-lasting carrier state develops, a condition that is associated with significant production and economic losses in the longer term [16, 17]. Additionally, carrier animals are important for the transmission of pathogens to feeding tick larvae, nymphs and/or adults. Over the last decade, molecular techniques such as species-specific polymerase chain reaction (PCR) and the reverse line blot (RLB) hybridisation assay have been widely used for detection and discrimination of Theileria, Babesia and Anaplasma species in animals [4, 8, 11, 18-20].

A number of studies on theileriosis and babesiosis of small ruminants have been previously performed in Turkey $[12,20,21]$ and $T$. ovis, Theileria sp. MK, Theileria sp. OT3, and B. ovis have been detected in some parts of the country [12, 22]. However, T. lestoquardi, T. luwenshuni, T. uilenbergi and Theileria sp. OT1 have not been previously reported. Anaplasma phagocytophilum and Ehrlichia sp. Omatjenne have been identified in cattle and in ticks collected from animals and humans [23-26]. Anaplasma ovis was also detected in ticks collected from animal shelters [27], however only limited information exists concerning ovine anaplasmosis [28, 29].

In the present study, the prevalence of Theileria, Babesia, Anaplasma and Ehrlichia species in small ruminants in 18 different provinces of Turkey was determined using species-specific single PCR and RLB hybridisation. The diagnostic sensitivity of the two tests was then compared in terms of their ability to detect single and mixed infections.

\section{Methods}

\section{Parasite material and sample collection}

The study was conducted in 18 different provinces representing five different geographical regions of Turkey (Fig. 1). A total of 1979 blood samples were collected from sheep $(n=1727)$ and goats $(n=252)$ between 2011 and 2013 from the selected provinces. Blood samples were collected in EDTA tubes from randomly selected animals in each herd that were at least one year of age. DNA was extracted from blood samples using the Promega Wizard genomic DNA extraction kit (Madison, WI, USA) following the manufacturer's instructions. Extracted DNA was resuspended in $100 \mu$ l elution buffer and stored at $-20{ }^{\circ} \mathrm{C}$ until analysed. Control DNA samples used in this study included isolates of $T$. ovis (Kayseri), Theileria sp. MK (Kayseri) and B. ovis (Kayseri) from Turkey, isolates of $T$. lestoquardi (Lahr) and B. crassa from Iran, isolates of $T$. uilenbergi (Longde), T. luwenshuni (Lintan) and B. motasi (Lintan) from China and an isolate of $A$. phagocytophilum from the United Kingdom.

\section{RLB hybridisation assay for the detection of Theileria, Babesia, Anaplasma and Ehrlichia species}

Samples were tested using the RLB hybridisation assay. The V4 hypervariable region of the $18 \mathrm{~S}$ and V1 hypervariable region of the $16 \mathrm{~S}$ small subunit ribosomal RNA gene of all Theileria, Babesia, Ehrlichia and Anaplasma species were amplified by PCR prior to RLB. Reactions were performed in a total volume of $50 \mu$ l containing $1 \times$ PCR buffer (ThermoFisher Scientific, Massachusetts, USA), $1.5 \mathrm{mM} \mathrm{MgCl}_{2}$ (Promega, Madison, WI, USA), $200 \mathrm{mM}$ of each deoxynucleotide triphosphate (dNTP), $2.5 \mathrm{U}$ of hotstart Taq polymerase (ThermoFisher Scientific, USA), 25 pmol of each primer: RLB-F, RLB-R (5' biotin-labelled), Ehr-F and Ehr-R (5' -biotin labelled) (Additional file 1: Table S1) and $2 \mu \mathrm{l}$ of template DNA. Reaction conditions comprised an initial denaturation step at $94{ }^{\circ} \mathrm{C}$ for $10 \mathrm{~min}$ followed by a touchdown programme employing two cycles at each temperature, i.e. $20 \mathrm{~s}$ at $94^{\circ} \mathrm{C}, 30 \mathrm{~s}$ at an annealing temperature of $67^{\circ} \mathrm{C}, 30 \mathrm{~s}$ at $72{ }^{\circ} \mathrm{C}$, with the annealing temperature being decreased from $67{ }^{\circ} \mathrm{C}$ to $57{ }^{\circ} \mathrm{C}$ in steps of $2{ }^{\circ} \mathrm{C}$. Following this, 40 cycles of $20 \mathrm{~s}$ at $94{ }^{\circ} \mathrm{C}, 30 \mathrm{~s}$ at $57{ }^{\circ} \mathrm{C}$ and $30 \mathrm{~s}$ at $72{ }^{\circ} \mathrm{C}$ were performed, followed by a final extension at $72{ }^{\circ} \mathrm{C}$ for $10 \mathrm{~min}$. Oligonucleotide sequences used in this study 


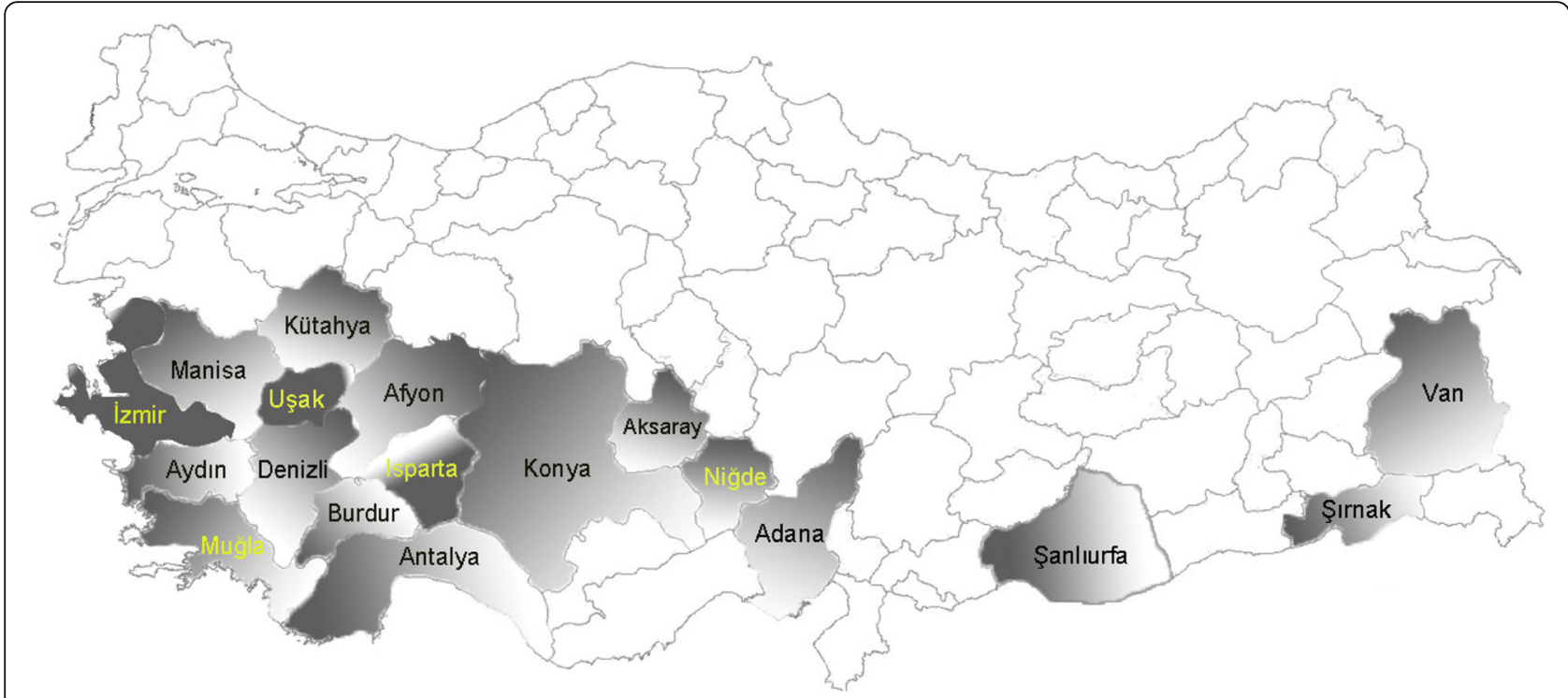

Fig. 1 Map of Turkey showing the provinces of five geographical regions where the samples were collected

are listed in Additional file 2: Table S2. $20 \mu \mathrm{l}$ of each 18S and $16 \mathrm{~S}$ biotin-labelled PCR products were screened by RLB hybridisation assay as previously described $[4,30]$ with a modification at the post-hybridisation washing step, which was performed at $52{ }^{\circ} \mathrm{C}$ for $10 \mathrm{~min}$. After examination and documentation, the membrane was washed twice in preheated $1 \%$ SDS at $80{ }^{\circ} \mathrm{C}$ for $30 \mathrm{~min}$, followed by washing in $100 \mathrm{ml} 20 \mathrm{mM}$ EDTA, pH 8, for $15 \mathrm{~min}$ at room temperature, then the membrane was covered in 20 mM EDTA, pH 8 and re-used about 15 times.

\section{Species-specific single PCR}

All 1979 samples were screened with an array of species-specific single PCRs for the presence of $T$. ovis, T. lestoquardi, T. uilenbergi, T. luwenshuni, Theileria sp. MK, B. ovis, A. ovis and A. phagocytophilum. Details of primer pairs for each species are given in Additional file 1: Table S1. PCR reactions were performed in a final volume of $25 \mu \mathrm{l}$ containing $10 \mathrm{mM}$ Tris- $\mathrm{HCl}$ (pH 8.3), $50 \mathrm{mM} \mathrm{KCl,} 1.5 \mathrm{mM} \mathrm{MgCl}_{2}$, $0.001 \%$ gelatin, $250 \mu \mathrm{M}$ of each deoxynucleotide triphosphate, $1 \mathrm{U}$ of HOT FIREPol DNA polymerase (Solis Biodyne, Tartu, Estonia), $10 \mu \mathrm{M}$ of forward and reverse primer and $2 \mu \mathrm{l}$ of template DNA. The reactions were performed using an automatic thermal cycler (Techne, TC-512, Staffordshire, UK) and reaction conditions are given in Additional file 3: Table S3. For each reaction, $10 \mu \mathrm{l}$ of PCR product were electrophoresed on a $1.5 \%$ agarose gel containing $10 \mu \mathrm{l} / \mathrm{ml}$ SybrGreen (SafeView ${ }^{\mathrm{Tm}}$, ABM Inc., Richmond, Canada) in Tris-acetate-EDTA (TAE) buffer at $100 \mathrm{~V}$ and visualised under UV light.

\section{Cloning and sequencing}

In order to confirm the specificity of the single PCRs, amplicons generated using $T$. ovis, T. uilenbergi, $T$. luwenshuni, Theileria sp. MK, B. ovis, A. ovis and A.phagocytophilum species-specific primers were sequenced. Briefly, gel purified (Qiagen Gel Purification Kit, Hilden, Germany) PCR products corresponding to each positive field sample, were cloned using the TOPO $^{\circ}$ TA Cloning ${ }^{\bullet}$ Kit (Invitrogen ${ }^{\mathrm{T}}$, ThermoFisher Scientific, USA). Plasmids containing amplified PCR products were purified using a plasmid purification kit (Qiagen, Germany), then sequenced using a commercial service (GATC Biotech, Konstanz, Germany). Theileria lestoquardi was not identified in any of the samples collected for this study and therefore no sequences of this parasite could be generated.

\section{Statistical analysis}

The Chi-square test was used to compare proportions of observed positivity in different regions and among different provinces. Observed differences were considered to be statistically significant when the resulting $P$-value was lower than 0.05. Agreement between the different diagnostic tests (PCR and RLB) assessing the presence of $A$. ovis, T. ovis, T. luwenshuni, T. uilenbergi, Theileria sp. MK and B. ovis was calculated. A kappa ( $\mathrm{K}$ ) measure of agreement test was performed to compare the performance of the two tests; $\kappa<0$ indicates no agreement beyond chance, while a $\mathrm{K}$-value between 0.81 and 0.99 indicates almost perfect agreement. A k-value between 0.41 and 0.60 indicates a moderate level of agreement [31, 32]. 


\section{Results}

Prevalence of Theileria, Babesia, Ehrlichia and Anaplasma spp. determined by RLB

The prevalence and distribution of single and mixedspecies infections are summarised in Table 1 and in Additional file 4: Table S4, respectively. The overall prevalence of haemoparasites detected by RLB was $74.78 \%$ with 1480 animals infected with at least one species. The prevalence of Theileria species was $64.1 \%$, whereas for Anaplasma and Babesia species it was 41 and $9.9 \%$ respectively. The most prevalent Theileria spp. was $T$. ovis with a prevalence of $60 \%$ (1188/1979), followed by Theileria sp. OT1 (2.6\%), T. uilenbergi (0.5\%), Theileria sp. MK (0.4\%) and Theileria sp. OT3 (0.2\%). Anaplasma ovis was the only Anaplasma species detected by RLB with an overall prevalence of 41.1\% (813/ 1979). An unclassified species of Babesia (denoted Babesia spp.) was found to be the most abundant (5.4\%) Babesia species. The prevalence of Babesia spp. was found to be significantly higher $\left(\chi^{2}=16.2, d f=3, P=0.001\right)$ in the Mediterranean region (7.3\%) than in other regions. The total prevalences of B. crassa and B. ovis were 4.0 and $0.4 \%$, respectively. Babesia motasi was detected only in two samples (0.1\%). Theileria lestoquardi, A. phagocytophilum, E. ruminantium, E. ovina and Ehrlichia spp. Omatjenne were not detected by RLB in any of the samples tested.

RLB detected single infections in 774 (39.1\%) of the 1979 animals (Table 1). Among these single infections, the most prevalent species was T. ovis (26.4\%), followed by $A$. ovis $(11.3 \%), B$. crassa $(0.7 \%)$, Theileria sp. OT1 (0.3\%) and B. motasi (0.1\%). Theileria ovis and A. ovis were detected in all regions. The proportion of mixed infections detected by RLB was $35.42 \%$ indicating that $701 / 1979$ animals were co-infected with multiple species (Additional file 4: Table S4). A variety of combinations of species was detected and the RLB was able to identify mixed infections with up to five species (Additional file 4: Table S4). A majority of the mixed infections $(80.74 \%$, 566/701) contained both $T$. ovis and A. ovis. Mixed infections, which did not include either of these species, were detected in only 11 (1.56\%) animals.

The highest prevalence of overall infections detected by RLB was in the Southeastern and Eastern Region (87.83\%) while the lowest $(70.77 \%)$ was in the Aegean Region. The prevalence (52.61\%) of single infections

Table 1 Single species infections detected by RLB and species-specific single PCR

\begin{tabular}{|c|c|c|c|c|c|c|c|c|c|c|c|c|c|c|c|c|c|c|c|}
\hline \multirow[t]{2}{*}{ Province } & \multirow{2}{*}{$\begin{array}{l}\text { No. of } \\
\text { animals }\end{array}$} & \multicolumn{10}{|c|}{ Detected by RLB (sheep/goat) } & \multicolumn{8}{|c|}{ Detected by PCR (sheep/goat) } \\
\hline & & $\overline{A . O}$ & T.O & T.sp.OT1 & T.sp.OT3 & T/B catchall & T.sp & B.o & B.sp & $B C$ & $\overline{B m}$ & $\overline{A . O}$ & B.o & T.O & T.I. & T.u. & T.le & T.MK & $\overline{A . p}$ \\
\hline Adana & 95 & $1 / 11$ & 18 & 1 & & & & & & & & $12 / 12$ & & 16 & & & & & \\
\hline Afyon & 100 & 1 & 52 & & & & & & & & & 1 & & 9 & & & & & \\
\hline Aksaray & 55 & 6 & 18 & & & & & & & 1 & & 10 & & 10 & & & & & \\
\hline Antalya & 95 & 8 & 25 & & & & & & & & & 9 & & 10 & & 9 & & & \\
\hline Aydın & 273 & 9 & 64 & & & & & & & & & $28 / 1$ & 2 & 44 & $10 / 1$ & $1^{\mathrm{a}}$ & & 1 & \\
\hline Burdur & 137 & $16 / 10$ & 37 & 1 & & & & & & 2 & & $13 / 9$ & & 18 & $1^{\mathrm{a}}$ & & & & \\
\hline Denizli & 140 & 3 & 53 & & & & & & & & & 4 & & 21 & & & & & \\
\hline Isparta & 55 & & 20 & & & & & & & & & 1 & & 11 & & & & & \\
\hline İzmir & 104 & 1 & $39 / 1$ & & 1 & & & & & & & 2 & & 20 & & & & $8 / 1$ & \\
\hline Konya & 75 & 3 & 23 & & & & 1 & & & 2 & & 3 & & 8 & & & & & \\
\hline Kütahya & 103 & $33 / 1$ & 3 & & & & & & 1 & & & $37 / 1$ & 1 & 3 & & & & & \\
\hline Manisa & 101 & $1 / 10$ & 19 & & & & & & & & & $5 / 30$ & $1^{a}$ & 10 & & & & & \\
\hline Muğla & 114 & $43^{\mathrm{a}}$ & & $2^{a}$ & & $1^{a}$ & & & & $1^{a}$ & $2^{a}$ & $51^{\mathrm{a}}$ & $1^{a}$ & & & & & & $7^{a}$ \\
\hline Niğde & 214 & 20 & 50 & 2 & & & & 1 & 2 & 1 & & 29 & 4 & 18 & 13 & & & & \\
\hline Şırnak & 98 & $4 / 33$ & $15 / 2$ & & & & & & & $1^{a}$ & & $2 / 30$ & $1^{a}$ & $13 / 3$ & & & & & \\
\hline Şanlıurfa & 100 & 1 & 52 & & & & & & & 3 & & 1 & & 41 & & & & & \\
\hline Uşak & 88 & 2 & 27 & & & & & & & 2 & & 4 & & 14 & & 1 & & 1 & \\
\hline Van & 32 & 6 & 5 & & & & & & & & & 1 & & 1 & & 1 & & & \\
\hline Total & 1979 & 223 & 523 & 6 & 1 & 1 & 1 & 1 & 3 & 13 & 2 & 296 & 10 & 270 & 25 & 12 & & 11 & 7 \\
\hline Percentag & & 11.3 & 26.4 & 0.3 & & & & & 0.2 & 0.7 & 0.1 & 15 & 0.5 & 13.6 & 1.3 & 0.6 & & 0.6 & 0.4 \\
\hline
\end{tabular}

Abbreviations: A.o Anaplasma ovis, B.o Babesia ovis, T.o Theileria ovis, T/B all samples that showed reactivity with Theileria/Babesia catchall probe and considered as T/B genus positive, $T$. $s p$ samples that showed reactivity with Theileria all probe and considered as Theileria spp. positive, $B$. $s p$ samples that showed reactivity with Babesia all probe and considered as Babesia spp positive, BcG Babesia crassa, Bm Babesia motasie, T.OT1 Theileria sp. OT1, T.OT3 Theileria sp. OT3, T.I Theileria luwenshuni, T.u Theileria uilenbergi, T.le Theileria lestoquardi, T.MK Theileria sp. MK, A.p Anaplasma phagocytophilum

${ }^{a}$ Number of positive samples collected from goats 
detected in southeastern / eastern region was significantly higher than other regions $\left(\chi^{2}=42.6, d f=6, P<0.0001\right)$ (Additional file 5: Figure S1a). The RLB approach did not detect any Babesia spp. in the southeastern/eastern region, while $B$. crassa was observed in all regions and $B$. ovis was detected in four provinces (Niğde, Kutahya, Izmir and Şırnak). The prevalences of T. uilenbergi and $B$. crassa in southeastern/eastern region were 2.2 and $10.4 \%$, respectively. Compared to other regions, significantly higher numbers of samples were found to be positive for both $T$. uilenbergi $\left(\chi^{2}=15.0, d f=3, P=\right.$ $0.002)$ and $B$. crassa $\left(\chi^{2}=32.7, d f=3, P<0.0001\right)$ in the southeastern/eastern region.

The highest prevalence of total infections (97.14\%) detected by RLB was in Denizli while the lowest (34.73\%) was in Antalya. Theileria luwenshuni and T. separata were both detected in two samples collected from Niğde province. In Antalya and Muğla, animals were solely infected with a single parasite species. In Afyon, Izmir, Manisa, Muğla, Şırnak and Şanlıurfa the prevalence of single infections was higher than that of mixed infections (Additional file 5: Figure S1b).
Prevalence of haemoparasite species determined by PCR The 1979 samples were screened with species-specific single PCRs for the presence of T. ovis, T. lestoquardi, $T$. uilenbergi, T. luwenshuni, Theileria sp. MK, B. ovis, A. ovis and A. phagocytophilum. The prevalence and distribution of single and mixed infections detected by PCR are given in Table 1 and in Additional file 6: Table S5, respectively. An overall prevalence was determined to be $84.1 \%$, indicating $1665 / 1979$ animals were infected with at least one species. The prevalence of the two most abundant species, A. ovis (63.3\%) and T. ovis (61.4\%), were very similar and much higher than the other species. None of the collected samples were found to be positive for T. lestoquardi by PCR.

The highest prevalence of $A$. ovis was found in the Central Anatolia region (68.7\%) with a statistically significant difference $\left(\chi^{2}=15.1, d f=3, P=0.002\right)$ among regions. Anaplasma ovis was detected in all provinces with the highest prevalence detected in Kütahya (92\%) and the lowest in Antalya (13\%) (Fig. 2). The prevalence of $A$. ovis also differed significantly $\left(\chi^{2}=308.9\right.$, $d f=17, P<0.0001)$ among provinces. The prevalence

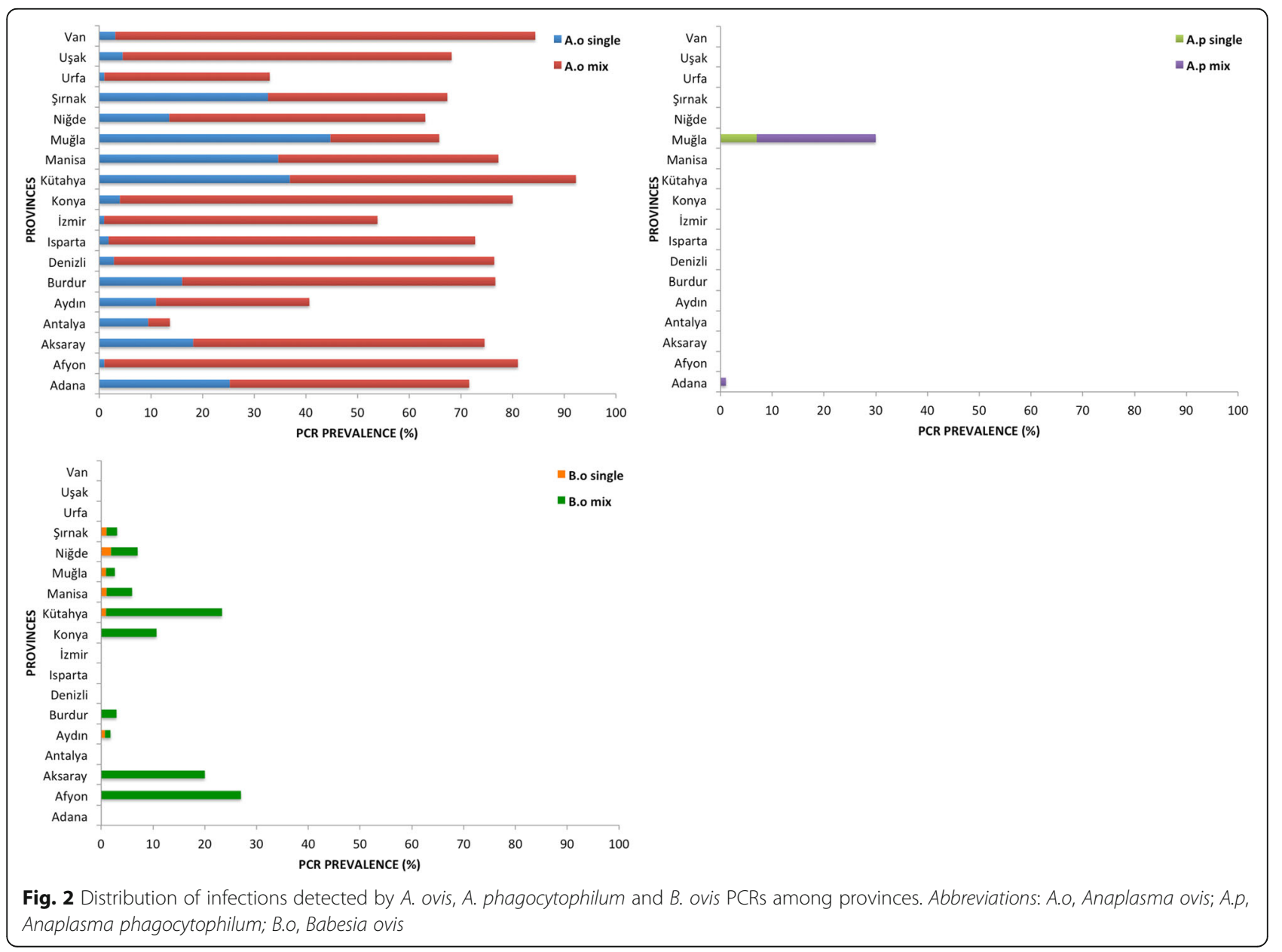


of A. phagocytophilum (2.9\%) detected in the Aegean region was significantly higher than other regions $\left(\chi^{2}=25.7\right.$, $d f=3, P<0.0001)$. This pathogen was only detected in goats in Muğla and Adana provinces (Fig. 2).

Theileria ovis was detected in all provinces, except Muğla. The highest infection rate was found in Afyon (97\%) and Isparta (96.4\%) and the lowest was in Antalya (14.7\%) (Fig. 3) and this difference was statistically significant $\left(\chi^{2}=537.6, d f=17, P<0.0001\right)$. The prevalence of $T$. ovis was found to be significantly different among regions $\left(\chi^{2}=14.7, d f=3, P=0.002\right)$ with the highest prevalences found in Central Anatolia (68.9\%) and southeastern/eastern regions $(66.1 \%)$. The prevalence of T. luwenshuni infection was statistically significantly different $\left(\chi^{2}=163,9, d f=3, P<0.0001\right)$ among regions and the highest prevalence was found in the Central Anatolia region (23.8\%). The highest infection rate was found in Niğde (38.3\%) and lowest was in Burdur (2\%) with a significance difference $\left(\chi^{2}=379.6, d f=17, \quad P<0.0001\right)$ among provinces.

The prevalence of $T$. uilenbergi was significantly different among regions $\left(\chi^{2}=35.6, d f=3, P<0.0001\right)$ and the highest prevalence was in the southeastern/eastern region
(11.7\%). The highest infection rate was found in Van (75\%), while the infection rate in Izmir (3\%), Kütahya (3\%) and Şanlıurfa (3\%) provinces was much lower (Fig. 3). The difference among provinces was statistically significant $\left(\chi^{2}=407.7, d f=17, \quad P<0.0001\right)$. The prevalence of Theileria sp. MK was statistically significantly different among regions $\left(\chi^{2}=27.3, d f=3, P<0.0001\right)$ with the highest prevalence detected in Aegean region (4.7\%).

PCR detected a total of 106 infections with $B$. ovis both as a single $(0.5 \%)$ and mixed infection (4.9\%) with up to four species. The prevalence of B. ovis was found to be significantly different among regions $\left(\chi^{2}=37.3, d f=3\right.$, $P<0.0001$ ) and the highest prevalence was found in Central Anatolia region $(9.9 \%)$. The prevalence of $B$. ovis in Afyon (27\%) was significantly higher than other provinces $\left(\chi^{2}=237.6, d f=17, P<0.0001\right)$.

PCR detected single infections in 631 (32\%) of 1979 animals, while mixed infections were observed in $52.2 \%$ of samples. Among samples with single infections, $A$. ovis and T. ovis were found at a considerably higher level than any other species. PCR results revealed that 28 different combinations of mixed infections occurred, some with up to four species (Additional file 6: Table S5). Of

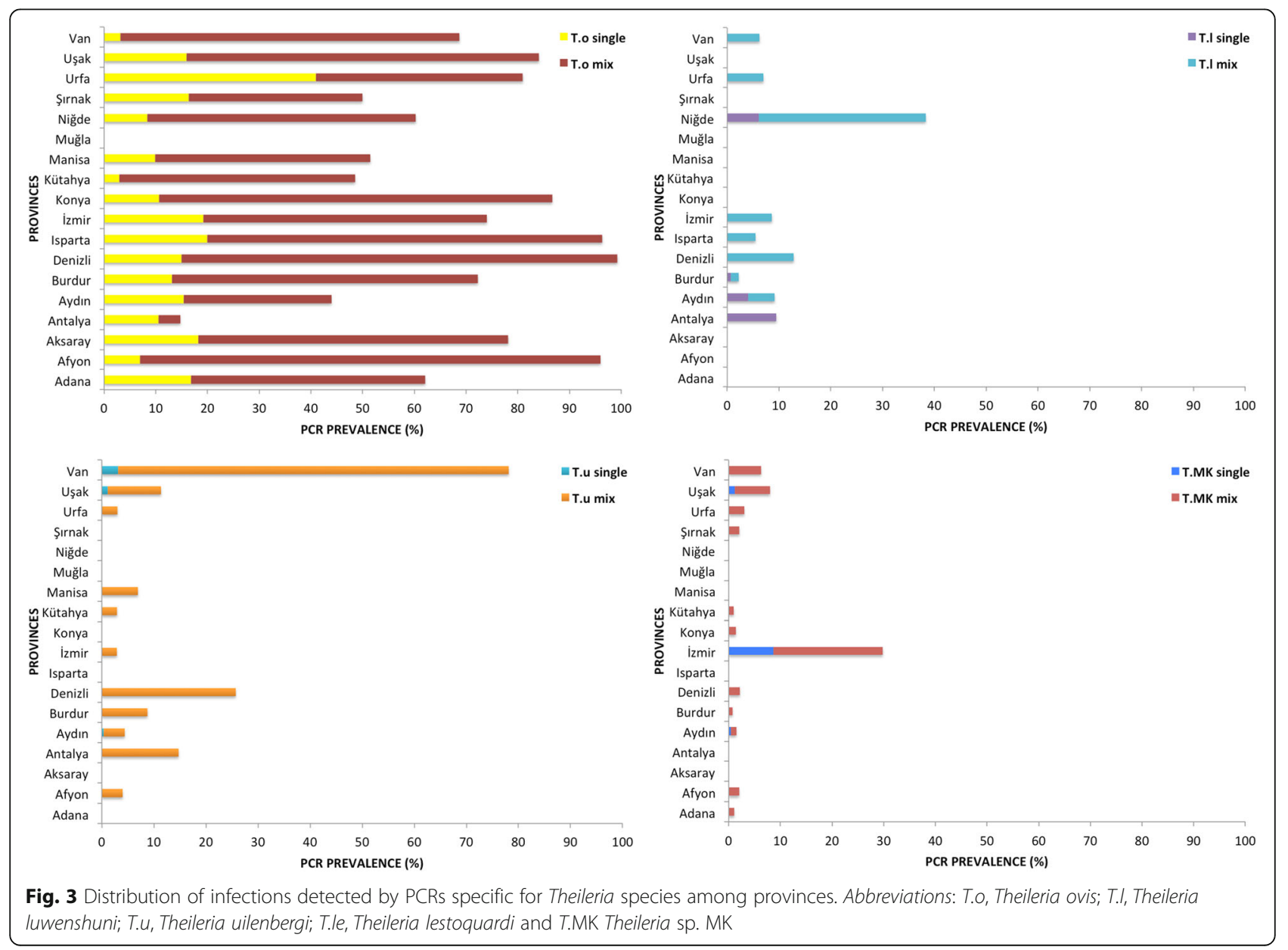


the 1034 samples containing a mixture of species, $64.3 \%$ (663/1031) contained both T. ovis and A. ovis and, overall, 99.61\% of samples with mixed infections (1029/1031) had at least one of these species present. The prevalence of mixed infections detected by PCR was found to be statistically significantly different among regions $\left(\chi^{2}=\right.$ 38.09, $d f=6, P<0.0001)$ and the highest prevalence was found in the Aegean region (27.13\%).

\section{Comparison of species-specific, single-PCR and RLB tests}

The observed prevalences of T. ovis $\left(\chi^{2}=998.4, d f=1\right.$, $P<0.0001), T$. luwenshuni $\left(\chi^{2}=12.2, d f=1, P<0.0001\right)$, Theileria sp. MK $\left(\chi^{2}=169.2, d f=1, P<0.0001\right)$ and $B$. ovis $\left(\chi^{2}=51.7, d f=1, P<0.0001\right)$ by PCR were significantly higher than that of RLB. Additionally, PCR detected a significantly higher $\left(\chi^{2}=285.7, d f=1, P<0.0001\right)$ number of $A$. ovis (1253/1979) infections compared to RLB. For T. uilenbergi, no significant difference was observed (Table 2). The kappa values when comparing PCR and RLB tests for A. ovis and T. ovis indicated a moderate $(\kappa=0.344)$ and a substantial $(\kappa=0.710)$ level of agreement, respectively, while for $T$. luwenshuni, T. uilenbergi, Theileria sp. MK and B. ovis the kappa values ranged from below zero to 0.179 indicating no agreement between PCR and RLB tests (Table 2).

Mixed infection was common among small ruminants and PCR results showed that 52.24\% (1034/1979) of the samples were co-infected, while RLB detected a coinfection rate of $35.42 \%$ (701/1979). The observed prevalence of mixed infections detected by PCR was significantly higher than that of $\operatorname{RLB}\left(\chi^{2}=586.7, d f=4\right.$, $P<0.0001$, Table 3$)$. The kappa value was 0.288 when comparing PCR and RLB tests for the presence of single and mixed infections indicating a slight or weak agreement between two tests [31, 32].

\section{Sequence analysis}

The specificity of the single PCRs was confirmed by sequencing PCR amplicons generated using T. ovis, $T$. uilenbergi, T. luwenshuni, Theileria sp. MK, B. ovis, A. ovis and $A$. phagocytophilum species-specific primer sets. When the sequence of each amplified fragment was compared with reference sequences in the NCBI database, the 520 bp T. ovis product (GenBank KY283961), the 388 bp T. luwenshuni product (GenBank KY283963) and the $870 \mathrm{bp}$ A. ovis product (GenBank KY283958)

Table 2 Comparison of PCR and RLB results

\begin{tabular}{|c|c|c|c|c|c|c|c|c|}
\hline \multirow[t]{2}{*}{ Species } & & & \multicolumn{2}{|l|}{ PCR } & \multirow[t]{2}{*}{ Total } & \multirow[t]{2}{*}{$P$-value } & \multicolumn{2}{|c|}{ Measurement of agreement ${ }^{a}$} \\
\hline & & & Positive & Negative & & & Kappa value & SD $(95 \% \mathrm{Cl})$ \\
\hline \multirow[t]{3}{*}{ A. ovis } & RLB & Positive & 693 & 120 & 813 & $<0.0001^{*}$ & 0.344 & 0.019 \\
\hline & & Negative & 560 & 606 & 1166 & & & \\
\hline & Total & & 1253 & 726 & 1979 & & & \\
\hline \multirow[t]{3}{*}{ T. ovis } & RLB & Positive & 1065 & 123 & 1188 & $<0.0001^{*}$ & 0.710 & 0.016 \\
\hline & & Negative & 150 & 641 & 791 & & & \\
\hline & Total & & 1215 & 764 & 1979 & & & \\
\hline \multirow[t]{3}{*}{ T. luwenshuni } & RLB & Positive & 1 & 0 & 1 & $<0.0001^{*}$ & 0.012 & 0.012 \\
\hline & & Negative & 148 & 1830 & 1978 & & & \\
\hline & Total & & 149 & 1830 & 1979 & & & \\
\hline \multirow[t]{3}{*}{ T. uilenbergi } & RLB & Positive & 0 & 10 & 10 & 0.404 & -0.009 & 0.003 \\
\hline & & Negative & 128 & 1841 & 1969 & & & \\
\hline & Total & & 128 & 1851 & 1979 & & & \\
\hline \multirow[t]{3}{*}{ Theileria sp. MK } & RLB & Positive & 6 & 1 & 7 & $<0.0001^{*}$ & 0.179 & 0.064 \\
\hline & & Negative & 52 & 1920 & 1972 & & & \\
\hline & Total & & 58 & 1921 & 1979 & & & \\
\hline \multirow[t]{3}{*}{ B. ovis } & RLB & Positive & 5 & 3 & 8 & $<0.0001^{*}$ & 0.081 & 0.035 \\
\hline & & Negative & 101 & 1870 & 1971 & & & \\
\hline & Total & & 106 & 1873 & 1979 & & & \\
\hline \multirow[t]{3}{*}{ A. phagocytophilum } & RLB & Positive & 0 & 0 & 0 & - & - & - \\
\hline & & Negative & 31 & 1948 & 1979 & & & \\
\hline & Total & & 31 & 1948 & 1979 & & & \\
\hline
\end{tabular}

${ }^{*} P$-values considered as statistically significant $(P<0.05)$ based on the Chi-square test

${ }^{a}$ Agreement expressed as kappa value when comparing PCR and RLB tests for A. ovis, T. ovis, T. luwenshuni, T. uilenbergi, Theileria sp. MK, B. ovis and A.

phagocytophilum two-by-two. None of the collected samples were found to be positive for T. lestoquardi by PCR and RLB 
Table 3 Comparison of single and mixed species infections detected by RLB and species-specific single PCR

\begin{tabular}{|c|c|c|c|c|c|c|c|c|}
\hline \multicolumn{2}{|c|}{ Type of infection } & \multicolumn{3}{|l|}{ RLB } & \multirow[t]{2}{*}{ Total } & \multirow[t]{2}{*}{$P$-value } & \multicolumn{2}{|c|}{ Measurement of agreement } \\
\hline & & Single & Mixed & Negative & & & Kappa value & $\mathrm{SD}(95 \% \mathrm{Cl})$ \\
\hline \multirow[t]{4}{*}{ PCR } & Single & 326 & 109 & 196 & 631 & & & \\
\hline & Mixed & 391 & 536 & 107 & 1034 & & & \\
\hline & Negative & 57 & 56 & 201 & 314 & & & \\
\hline & Total & 774 & 701 & 504 & 1979 & $<0.0001^{*}$ & 0.288 & 0.017 \\
\hline
\end{tabular}

*P-values considered as statistically significant $(P<0.05)$ based on the Chi-square test

showed $100 \%$ identity with isolates and clones available in the database. The 389 bp T. uilenbergi product (GenBank KY283964) showed $100 \%$ identity with $18 \mathrm{~S}$ ribosomal RNA genes of T. uilenbergi isolate Li 2 and the $757 \mathrm{bp}$ Theileria sp. MK product (GenBank KY283962) showed 99\% identity with $18 \mathrm{~S}$ ribosomal RNA genes of Theileria sp. MK from sheep. The 549 bp B. ovis product (GenBank KY283960) showed 99\% identity with small subunit ribosomal RNA genes of a number of $B$. ovis isolates. The $849 \mathrm{bp}$ A. phagocytophilum product (GenBank KY283959) showed $97 \%$ identity to $m s p$ genes of a number of $A$. phagocytophilum isolates (data not shown).

\section{Discussion}

\section{Prevalence of TBHDs detected by PCR and RLB}

Despite the widespread distribution of ovine tick-borne haemoparasitic diseases in tropical and subtropical regions of the world [33] and their constraint to livestock production $[1,15,29,34]$, relatively limited information on their abundance and distribution is currently available [33]. Theileriosis and babesiosis are the two most extensively studied tick-borne haemoparasitic diseases occurring in small ruminants in Turkey; however only limited information exists on ovine anaplasmosis. In the present study, a comprehensive investigation of the distribution and prevalence of ovine haemoparasites in 18 provinces of Turkey was undertaken. To this end, two approaches were utilised, RLB hybridisation assay and species-specific PCR.

In previous studies, Theileria species such as Theileria sp. (15\%), T. ovis (15-92\%), Theileria sp. MK (1-2\%) and Theileria sp. OT3 (0.4\%) were detected in Central Anatolia [21, 35], Eastern and Southeastern Anatolia and the Black Sea region $[12,20]$ of Turkey. In this study, RLB (60\%) and PCR (61.4\%) results revealed that T. ovis is the most prevalent parasite in all provinces, except in Mugla. Theileria ovis is transmitted by Rhipicephalus ticks trans-stadially [36] and these ticks play an important role in the transmission of the parasite in Turkey [20]. Theileria ovis has also been detected in salivary glands of $R$. bursa [37] which was reported as the major species of tick found on sheep and goats in the Black Sea region [38]. Considering that evidence demonstrating the existence of Rhipicephalus species such as $R$. bursa, $R$. sanguineus and $R$. turanicus in Mugla (unpublished data), it is unclear why $T$. ovis was not be detected in the present study. In this province samples were mostly collected from domestic goats; whether widening the sampling to sheep would result in detection of the parasite in this region remains to be determined.

The results obtained from the RLB assay revealed a low prevalence of Theileria sp. MK (0.4\%) and Theileria sp. OT3 (0.2\%), similar to previously reported prevalence rates in East Anatolia and the Black Sea region [12, 20, 39]. A higher prevalence of Theileria sp. MK was noted (2.9\%) when samples are screened by species-specific PCR. At present, no reliable information exists about the pathogenicity and vectors of these species in Turkey.

Theileria luwenshuni and T. uilenbergi are considered to be highly pathogenic for small ruminants [2]. These two parasites have been detected in China [3, 40] and Iraq [29] and recent evidence suggests the distribution of T. luwenshuni extends as far as the UK [41]. A study conducted in Iran revealed the presence of $T$. luwenshuni in sheepdog isolates [42]. The present study revealed the presence of Theileria sp. OT1, T. luwenshuni and T. uilenbergi in Turkey for the first time, demonstrating a broader distribution of these species than previously assumed. The distribution of $T$. luwenshuni and T. uilenbergi extended from the far east of the country (Van) to the far west (Izmir) of Turkey encompassing provinces located in different regions (Fig. 3). These species occurred as co-infections rather than single infections. Theileria uilenbergi has previously been detected as a coinfection of sheep with $A$. ovis and/or T. ovis in northern Iraq [29]. There is a possibility that $T$. luwenshuni and $T$. uilenbergi have been introduced to Turkey from northern Iraq and/or Iran with the movement/migratory pattern of domestic small ruminants and/or wild ruminants. Alternatively, they may have existed undetected in Turkey for a considerable period. Haemaphysalis qinghaiensis and $H$. longicornis have been shown to be responsible for transmitting T. luwenshuni and T. uilenbergi in China [43]. A relationship between $T$. luwenshuni/Theileria sp. OT1 and a Haemaphysalis spp. was suggested in a previous study [33] and $H$. punctata nymphs were suspected of the introduction of T. luwenshuni to the UK [41]. Haemaphysalis spp. such as $H$. parva, $H$. sulcata and $H$. punctata 
have been detected in various regions of Turkey [44]. Theileria lestoquardi, the cause of malignant theileriosis, has never been documented in Turkey, which is surprising since it has been detected in the neighbouring countries of Iran [45] and Iraq [29].

Babesia ovis, B. motasi and B. crassa cause ovine babesiosis in small ruminants [7]. Of these species, B. ovis is highly pathogenic for sheep and goats [46] and has been detected in Central, Eastern and South-eastern Anatolia regions $[21,22]$ with a prevalence ranging from 2 to $41 \%$. Results gathered in this study indicated a broader distribution of $B$. ovis in Aegean and Mediterranean regions compared to other regions (Fig. 2). Babesia motasi and B. crassa are considered to be pathogenic and mild or nonpathogenic for sheep and goats, respectively [7]. Haemaphysalis ticks are responsible for transmitting $B$. motasi [7] and B. crassa has been detected in Haemaphysalis ticks in both continental Europe and in Turkey [47, 48]. Theileria separata has been described as a nonpathogenic parasite of sheep [49] and Rhipicephalus evertsi has been implicated in its transmission [50]. In Turkey, the presence of B. motasi, B. crassa and T. separata in small ruminants has been suspected for several years. Although, Babesia motasi infection in sheep and goats has been reported in Mediterranean, Central Anatolia and Eastern regions of Turkey between 1954 and 1989 [51], it was unknown whether this pathogen is currently present. Babesia crassa has been detected in ixodid ticks collected from humans [24] while $T$. separata has not been reported previously. This is the first molecular confirmation of B. motasi, B. crassa and $T$. separata in small ruminants in Turkey. Results indicate that the ovine Babesia species detected in this study were sporadically distributed in the Aegean, Mediterranean, eastern and southeastern Anatolia regions. The distribution of Babesia spp. overlaps with the distribution of transmitting Rhipicephalus and Haemaphysalis ticks [7]. In this study, an unclassified Babesia spp. was also detected by RLB with a prevalence of $5.4 \%$ and, like $B$. crassa, it was abundantly detected in concurrent infections with other species (5.25\%).

Ovine anaplasmosis caused by $A$. ovis, is a tick-borne disease affecting sheep and goats [52]. Distribution of $A$. ovis extends from northern and southern Europe, Hungary to the Middle East and Cyprus [53-56]. In Turkey, A. ovis has been detected in ticks collected from animal shelters [27]. It has been proposed that relatively low productivity of local breeds might be related to infection with various tick-borne pathogens, including $A$. ovis [51]. Anaplasma ovis infection may predispose small ruminants to other fatal diseases and severe diseases have been described in bighorn sheep [57] and goats [58]. Of the tick-borne haemoparasitic diseases investigated in the present study, ovine anaplasmosis was found to be one of the most prevalent with approximately $70 \%$ of animals carrying A. ovis. Approximately $80 \%$ of the mixed infections detected in the present study were found to involve $A$. ovis, however, no clear impact of $A$. ovis infection in terms of clinical significance could be deduced. The existence of ixodid ticks transmitting A. ovis such as Haemaphysalis, Dermacentor, Rhipicephalus and Hyalomma $[43,59]$ has been reported in Central Anatolia region and in Aegean region [44] with their seasonal activity affecting the distribution of disease.

Anaplasma phagocytophilum is a pathogenic rickettsial organism causing tick-borne fever (TBF) in domestic animals and wild ruminants [9] with a world-wide distribution [60-62]. It was previously identified in domestic farm animals in Turkey $[26,28]$ although limited information on its impact on small ruminants exists [23, 28]. In the present study, $A$. phagocytophilum was only detected in goats, with 30 of the 31 positives coming from Mugla province. Both single (22.6\%) and mixed (77.4\%) infections were detected including one animal found to be co-infected with $A$. ovis. In previous studies, the prevalence of co-infections with $A$. ovis and $A$. phagocytophilum ranged from 6.5 to $22.22 \%$ in sheep with only a single infection with $A$. ovis detected in goats $[55,56]$. Ixodes ricinus is the main vector of $A$. phagocytophilum throughout Europe. In Turkey, A. phagocytophilum has been detected in tick species like Haemaphysalis sulcata, Rhipicephalus bursa and Ixodes ricinus [23-25]. It is accepted that $A$. phagocytophilum is not host specific and that human isolates may cause infections in animals and vice versa [63]. Therefore, the higher prevalence of $A$. phagocytophilum detected in the present study suggests that the risk of transmitting this pathogen to humans may be higher than previously anticipated. It is important to note that $A$. phagocytophilum was detected in wild goats inhabiting the Marmaris National Park within the Mugla Province (unpublished data). As there is no physical barrier between wildlife and grazing animals in this area, wildlife might play a role in transmitting this pathogen to domestic animals.

Ehrlichia spp. Omatjenne has previously been reported in cattle and in ixodid ticks feeding on cattle in Turkey $[25,26]$. However, none of the samples analysed in the present study were found to be positive for this pathogen.

\section{The rate of mixed infections and risk factors}

The results of the present study illustrate that mixed infection of tick-borne pathogens are very common in small ruminants in Turkey. Risk factors that may influence the prevalence of TBHDs include age and immune status of the host population [64-66] and the distribution and seasonal activity of ticks $[65,66]$. Potential vectors of these TBHDs have been reported in different parts of Turkey in the Black Sea, Mediterranean, 
southeastern, central Anatolia, eastern and Aegean regions $[38,44]$. Our results highlight that although infections with T. ovis and/or A. ovis appear to be the main risk for small ruminants, there is also a clear risk of co-infection with species including T. luwenshuni, T. uilenbergi, B. ovis, B. crassa, Babesia spp. and A. phagocytophilum.

Host species susceptibility to tick-borne pathogens also plays a role in determining prevalence of disease. Goats are known to be more resistant to T. lestoquardi than sheep, however there is no evidence to suggest that sheep and goats differ in their susceptibility or resistance to other tick-borne pathogen species [2]. The results of the present study illustrate that sheep harbour significantly higher $(P<0.0001)$ numbers of single and/or mixed infections than goats (Table 4). At a species level, significantly higher $(P<0.0001)$ numbers of $T$. ovis, $T$. luwenshuni, T. uilenbergi and Babesia spp. infections were detected in sheep. In contrast to these, $B$. motasi and $A$. phagocytophilum were only detected in goats.

The presence of multiple pathogens within an individual host may affect the outcome of infection. Co-infection with either Theileria ovis, A. ovis and B. ovis that are known to be non-pathogenic, mild pathogenic and highly pathogenic, respectively, can dramatically change the prognosis and increase the risk of severe disease and mortality. Additionally, it is known that TBF causes immunosuppression and infected animals become susceptible to secondary bacterial infections [67] that may result in decreased productivity and, in some cases, death [9]. It has been suggested that the outcome of concurrent infection with $A$. ovis and $B$. ovis can be more severe than a single infection alone [29]. Thus, co-infection with $A$. ovis/A. phagocytophilum and B. ovis may be associated with a poor prognosis and economic loss. Testing for only the major pathogen species may therefore underestimate the overall risk to livestock. Thus, assays that provide more comprehensive results will provide a better assessment of the impact on livestock productivity of co-infecting pathogens.

\section{Comparison of PCR and RLB}

In field conditions, a proportion of animals will exist in a carrier state, not showing overt signs of disease. Detection of carriers is important, as these animals play a critical role in epidemiology of TBHDs by acting as reservoirs of infection for naive ticks and through movement they may introduce disease to new regions. For epidemiological studies, the requirement for a method capable of simultaneously detecting and discriminating these pathogens and other piroplasms is clear [68]. Molecular techniques, such as individual PCR, designed to detect single species have become very popular over the last two decades. In contrast, the RLB assay has the capacity to simultaneously detect and discriminate multiple species within a sample $[4,30]$. In the present study, the efficacy of RLB hybridisation and species-specific PCR was compared in terms of their ability to detect single and mixed infections. For the detection of $A$. ovis, T. ovis, T. luwenshuni, T. uilenbergi, Theileria sp. MK, B. ovis and $A$. phagocytophilum, agreement between two tests ranged from none to moderate (Table 2). For A. ovis, nearly half (45\%) of PCR positives were found to be negative with RLB, however only $12.3 \%$ of the T. ovis PCR positives were found to be negative with RLB (Table 2). Similarly, in a previous study, T. lestoquardi and $B$. ovis were detected using species-specific PCR in samples that were negative by RLB [29]. Variables such as the amount of template DNA in carrier animals $[69,70]$, the presence of multiple parasites in one sample [19] as well as competition for a finite amount of reagents between primers affect the amount of each product generated during the PCR reaction [71, 72]. This may compromise the efficacy of the test to amplify all parasite genotypes resulting a reduction in sensitivity and thus an underestimation of herd infection rates in comparison to

Table 4 Numbers of single and mixed species infections detected by RLB and PCR (no. of positive samples/no. of collected)

\begin{tabular}{|c|c|c|c|c|c|c|c|c|}
\hline \multirow{3}{*}{$\begin{array}{l}\text { Region (no. of sheep/ } \\
\text { goat samples) }\end{array}$} & \multicolumn{4}{|c|}{ Sheep $(n=1727)^{\mathrm{b}, \mathrm{a}}$} & \multicolumn{4}{|c|}{ Goats $(n=252)^{\mathrm{b}, \mathrm{a}}$} \\
\hline & \multicolumn{2}{|c|}{ Single infection } & \multicolumn{2}{|c|}{ Mixed infection } & \multicolumn{2}{|c|}{ Single infection } & \multicolumn{2}{|c|}{ Mixed infection } \\
\hline & $\begin{array}{l}\text { Detected by } \\
\text { RLB }\end{array}$ & $\begin{array}{l}\text { Detected by } \\
\text { PCR }\end{array}$ & $\begin{array}{l}\text { Detected by } \\
\text { RLB }\end{array}$ & $\begin{array}{l}\text { Detected by } \\
\text { PCR }\end{array}$ & $\begin{array}{l}\text { Detected by } \\
\text { RLB }\end{array}$ & $\begin{array}{l}\text { Detected by } \\
\text { PCR }\end{array}$ & $\begin{array}{l}\text { Detected by } \\
\text { RLB }\end{array}$ & $\begin{array}{l}\text { Detected by } \\
\text { PCR }\end{array}$ \\
\hline Aegean $(863 / 160)$ & $311 / 863$ & $226 / 863$ & $353 / 863$ & $511 / 863$ & $61 / 160$ & $95 / 160$ & $0 / 160$ & $24 / 160$ \\
\hline Mediterranean (350/32) & $129 / 350$ & $99 / 350$ & $125 / 350$ & $171 / 350$ & $21 / 32$ & $22 / 32$ & $1 / 32$ & $6 / 32$ \\
\hline Central Anatolia (332/12) & $130 / 332$ & $95 / 332$ & $141 / 332$ & $217 / 332$ & $0 / 12$ & $0 / 12$ & $0 / 12$ & $0 / 12$ \\
\hline Eastern Anatolia (32/0) & $11 / 32$ & $3 / 32$ & $16 / 32$ & $28 / 32$ & $0 / 0$ & $0 / 0$ & $0 / 0$ & $0 / 0$ \\
\hline Southeastern Anatolia (150/48) & $75 / 150$ & $57 / 150$ & $58 / 150$ & $72 / 150$ & $36 / 48$ & $34 / 48$ & $7 / 48$ & $2 / 48$ \\
\hline Total & $656 / 1727$ & $480 / 1727$ & $693 / 1727$ & $1001 / 1727$ & $118 / 252$ & $151 / 252$ & $8 / 252$ & $32 / 252$ \\
\hline Percentage & 33.1 & 24.3 & 35 & 50.6 & 6 & 7.7 & 0.4 & 1.6 \\
\hline
\end{tabular}

${ }^{a}$ Statistically significant difference $(P<0.0001)$ between sheep and goats in terms of single and mixed infections detected by RLB and PCR

${ }^{\mathrm{b}}$ Total number of samples collected from each species 
RLB [19, 30]. Thus, in the case of single PCR assays when applied to samples containing a single species of pathogen, a high proportion of particular template DNA together with a lack of competition among primers would be predicted to result in a more sensitive reaction and a higher yield of amplicon. This was supported by the results obtained in the present study in which a statistically higher $(\mathrm{P}<0.0001$, Table 3$)$ number of mixed infections were detected by PCR (52.24\%) than RLB (35.42\%). Interestingly, all RLB-positive samples for $T$. uilenbergi were found to be negative with species-specific PCR (Table 2). This difference between the two tests was observed in samples having multiple species and may be attributed to a low parasitaemia [73].

\section{Conclusions}

The results obtained in this study indicate that the prevalence and distribution of Theileria, Babesia, Anaplasma and Ehrlichia species in small ruminants are complex and mixed infections are common throughout Turkey. Also, it should be appreciated that the failure to detect particular species in some regions does not necessarily indicate the absence of these pathogens. In order to assess risk factors associated with TBHDs and to improve design of costeffective control strategies, it is important to utilise accurate diagnostic tests in the field [66]. It can be concluded from these observations that RLB is capable of detecting most, but not all, of the mixed infections in some blood samples and that the diagnostic sensitivity of species-specific, single PCR was superior. Therefore, the use of species-specific single PCR is recommended to better estimate the prevalence in regions characterised by high transmission rates where a large proportion of animals are co-infected.

\section{Additional files}

Additional file 1: Table S1. Primers used for species-specific single PCR and 18S/16S PCRs for RLB hybridisation. (DOCX $92 \mathrm{~kb}$ )

Additional file 2: Table S2. Sequences and specificity of oligonucleotide probes used for RLB hybridisation assay. (DOCX $111 \mathrm{~kb}$ )

Additional file 3: Table S3. Conditions for each species-specific single PCR. (DOCX $70 \mathrm{~kb}$ )

Additional file 4: Table S4. Mixed species infections detected by RLB. (DOCX $116 \mathrm{~kb}$ )

Additional file 5: Figure S1. Distribution of single, mixed and total infections detected by RLB in each region (a) and among 18 provinces (b). (DOCX $2154 \mathrm{~kb})$

Additional file 6: Table S5. Mixed species infections detected by species-specific single PCR. (DOCX $101 \mathrm{~kb}$ )

Additional file 7: Figure S2. Distribution of single, mixed and total infections detected by PCR in each region (a) and among 18 provinces (b). (DOCX $1785 \mathrm{~kb})$

\section{Abbreviations}

RLB: Reverse line blotting; TBF: Tick-borne fever; TBHDs: Tick borne haemoparasitic diseases

\section{Acknowledgements}

The authors would like to thank Professor Jabbar Ahmed for providing $T$. lestoquardi, T. uilenbergi (Theileria sp. China 2), T. luwenshuni (Theileria sp. China 1) and B. motasi control DNA samples. We would also like to thank Professor Munir Aktas and his collaborators for providing T. ovis, B. ovis, Theileria sp. MK control DNA samples. Special thanks to Dr Alexander Gray for providing A. phagocytophilum positive control DNA. Samples collected from wild goats were kindly provided by Forest and Water Ministry, Directorate of $4^{\text {th }}$ district in accordance with the protocol signed between the two sides (Protocol number; 51133611-445-153017 dated 22/07/2014). This work is also dedicated to the great memory of Ulrike Seitzer.

\section{Funding}

Financial support for this study was provided by a Grant from EU, FP7 programme (KBBE-3-245145-PIROVAC) and a fund from the University of Adnan Menderes, Scientific Research Programs (Project no. VTF-13001).

\section{Availability of data and materials}

All data generated or analysed during this study are included in the article and its Additional files 1, 2, 3, 4, 5, 6 and 7 .

\section{Authors' contributions}

HBB wrote the manuscript and participated in the design of the study, sample collection and molecular analysis of samples. SB and OK carried out the sample collection and performed the statistical analysis. OK and AHU carried out molecular testing of samples and analysis. SH and HE participated in the study design and co-ordination, and drafted the final manuscript. WW participated in the critical reading of the publication and collaborated in the data analysis. TK participated in the design of the study, sample collection, interpreted data and critically revised the manuscript. All authors read and approved the final manuscript.

\section{Competing interests}

The authors declare that they have no competing interests.

\section{Consent for publication}

Not applicable.

\section{Ethics approval}

This study was approved by the Adnan Menderes University Animal Experiment Ethic Committee dated 28/08/2012 in accordance with decision number B.30.2.ADÜ.0.00.00.00/050.04/2012/047.

\section{Publisher's Note}

Springer Nature remains neutral with regard to jurisdictional claims in published maps and institutional affiliations.

\section{Author details}

${ }^{1}$ Department of Parasitology, University of Adnan Menderes, Faculty of Veterinary Medicine, 09016 Isıkl/Aydın, Turkey. ${ }^{2}$ Department of Veterinary Medicine, University of Yuzuncu Yil, Vocational high School of Gevas, Programme of Laboratorian and Veterinary Health, 65700 Van, Turkey. ${ }^{3}$ School of Veterinary Medicine, College of Medical, Veterinary and Life Sciences, University of Glasgow, Bearsden Road, Glasgow G61 1QH, UK.

Received: 6 September 2016 Accepted: 21 April 2017

Published online: 27 April 2017

References

1. Jongejan F, Uilenberg G. Ticks and control methods. Rev Sci Tech. 1994; 13(4):1201-26

2. Yin H, Schnittger L, Luo JX, Seitzer U, Ahmed JS. Ovine theileriosis in China: a new look at an old story. Parasitol Res. 2007;101:S191-5.

3. Schnittger L, Yin H, Gubbels MJ, Beyer D, Niemann S, Jongejan F, et al. Phylogeny of sheep and goat Theileria and Babesia parasites. Parasitol Res. 2003;91(5):398-406.

4. Schnittger L, Yin H, Qi B, Gubbels MJ, Beyer D, Niemann S, et al. Simultaneous detection and differentiation of Theileria and Babesia parasites infecting small ruminants by reverse line blotting. Parasitol Res. 2004;92(3):189-96. 
5. Ahmed JS, Luo JX, Scnittger L, Seitzer U, Jongejan F, Yin H. Phylogenetic position of small-ruminant infecting piroplasms. In: Blouin EF, Maillard JC, editors. Impact of emerging zoonotic diseases on animal health, vol. 1081. 2006. p. 498-504.

6. Yin H, Liu Z, Guan G, Liu A, Ma M, Ren Q, et al. Detection and differentiation of Theileria luwenshuni and T. uilenbergi infection in small ruminants by PCR. Transbound Emerg Dis. 2008;55(5-6):233-7.

7. Uilenberg G. Babesia-a historical overview. Vet Parasitol. 2006;138(1-2):3-10.

8. Bekker CP, de Vos S, Taoufik A, Sparagano OA, Jongejan F. Simultaneous detection of Anaplasma and Ehrlichia species in ruminants and detection of Ehrlichia ruminantium in Amblyomma variegatum ticks by reverse line blot hybridization. Vet Microbiol. 2002;89(2-3):223-38.

9. Dumler JS, Barbet AF, Bekker CP, Dasch GA, Palmer GH, Ray SC, et al. Reorganization of genera in the families Rickettsiaceae and Anaplasmataceae in the order Rickettsiales: unification of some species of Ehrlichia with Anaplasma, Cowdria with Ehrlichia and Ehrlichia with Neorickettsia, descriptions of six new species combinations and designation of Ehrlichia equi and 'HGE agent' as subjective synonyms of Ehrlichia phagocytophila. Int J Syst Evol Microbiol. 2001;51(Pt 6):2145-65.

10. Hornok S, Elek V, de la Fuente J, Naranjo V, Farkas R, et al. First serological and molecular evidence on the endemicity of Anaplasma ovis and $A$. marginale in Hungary. Vet Microbiol. 2007;122(3-4):316-22.

11. Nagore D, Garcia-Sanmartin J, Garcia-Perez AL, Juste RA, Hurtado A. Identification, genetic diversity and prevalence of Theileria and Babesia species in a sheep population from Northern Spain. Int J Parasitol. 2004; 34(9):1059-67.

12. Altay $K$, Aktas M, Dumanli N. Theileria infections in small ruminants in the east and southeast Anatolia. Turkiye Parazitol Derg. 2007;31(4):268-71.

13. Luo J, Yin $\mathrm{H}$. Theileriosis of sheep and goats in China. Trop Anim Health Prod. 1997;29(4 Suppl):8S-10.

14. Kirvar E, Ilhan T, Katzer F, Wilkie G, Hooshmand-Rad P, Brown D. Detection of Theileria lestoquardi (hirci) in ticks, sheep, and goats using the polymerase chain reaction. Ann N Y Acad Sci. 1998;849:52-62.

15. Jonsson NN, Bock RE, Jorgensen WK. Productivity and health effects of anaplasmosis and babesiosis on Bos indicus cattle and their crosses, and the effects of differing intensity of tick control in Australia. Vet Parasitol. 2008;155(1-2):1-9.

16. Gharbi M, Sassi L, Dorchies P, Darghouth MA. Infection of calves with Theileria annulata in Tunisia: economic analysis and evaluation of the potential benefit of vaccination. Vet Parasitol. 2006;137(3-4):231-41.

17. Uilenberg G. International collaborative research-significance of tick-borne hemoparasitic diseases to world animal health. Vet Parasitol. 1995;57(1-3):19-41.

18. M'Ghirbi Y, Ros-Garcia A, Iribar P, Rhaim A, Hurtado A, Bouattour A. A molecular study of tick-borne haemoprotozoan parasites (Theileria and Babesia) in small ruminants in Northern Tunisia. Vet Parasitol. 2013:198(1-2):72-7.

19. Eygelaar D, Jori F, Mokopasetso M, Sibeko KP, Collins NE, Vorster I, et al. Tick-borne haemoparasites in African buffalo (Syncerus caffer) from two wildlife areas in Northern Botswana. Parasit Vectors. 2015;8:26.

20. Altay K, Dumanli N, Aktas M. A study on ovine tick-borne hemoprotozoan parasites (Theileria and Babesia) in the East Black Sea Region of Turkey. Parasitol Res. 2012;111(1):149-53.

21. Inci A, Ica A, Yildirim A, Duzlu O. Identification of Babesia and Theileria species in small ruminants in Central Anatolia (Turkey) via reverse line blotting. Turk J Vet Anim Sci. 2010;34(2):205-10.

22. Aktas M, Altay K, Dumanli N. Determination of prevalence and risk factors for infection with Babesia ovis in small ruminants from Turkey by polymerase chain reaction. Parasitol Res. 2007;100(4):797-802.

23. Sen E, Uchishima Y, Okamoto Y, Fukui T, Kadosaka T, Ohashi N, et al. Molecular detection of Anaplasma phagocytophilum and Borrelia burgdorferi in Ixodes ricinus ticks from Istanbul metropolitan area and rural Trakya (Thrace) region of north-western Turkey. Ticks Tick Borne Dis. 2011;2(2):94-8.

24. Aktas M. A survey of ixodid tick species and molecular identification of tickborne pathogens. Vet Parasitol. 2014;200(3-4):276-83.

25. Aktas M, Altay K, Ozubek S, Dumanli N. A survey of ixodid ticks feeding on cattle and prevalence of tick-borne pathogens in the Black Sea region of Turkey. Vet Parasitol. 2012;187(3-4):567-71.

26. Aktas M, Ozubek S. Bovine anaplasmosis in Turkey: first laboratory confirmed clinical cases caused by Anaplasma phagocytophilum. Vet Microbiol. 2015;178(3-4):246-51.

27. Aktas M, Altay K, Dumanli N, Kalkan A. Molecular detection and identification of Ehrlichia and Anaplasma species in ixodid ticks. Parasitol Res. 2009;104(5):1243-8.
28. Gokce HI, Genc O, Akca A, Vatansever Z, Unver A, Erdogan HM. Molecular and serological evidence of Anaplasma phagocytophilum infection of farm animals in the Black Sea Region of Turkey. Acta Vet Hung. 2008;56(3):281-92.

29. Renneker S, Abdo J, Bakheit MA, Kullmann B, Beyer D, Ahmed J, et al. Coinfection of sheep with Anaplasma, Theileria and Babesia species in the Kurdistan Region, Iraq. Transbound Emerg Dis. 2013;60 Suppl 2:113-8.

30. Oura CAL, Bishop RP, Wampande EM, Lubega GW, Tait A. Application of a reverse line blot assay to the study of haemoparasites in cattle in Uganda. Int J Parasitol. 2004;34:603-13.

31. Viera AJ, Garrett JM. Understanding interobserver agreement: the kappa statistic. Fam Med. 2005;37(5):360-3.

32. McHugh ML. Interrater reliability: the kappa statistic. Biochem Medica. 2012; 22(3):276-82

33. Ros-Garcia A, Barandika JF, Garcia-Perez AL, Juste RA, Hurtado A. Assessment of exposure to piroplasms in sheep grazing in communal mountain pastures by using a multiplex DNA bead-based suspension array. Parasit Vectors. 2013;6(1):277.

34. Cicek H, Cicek H, Eser M, Tandogan M. Current status of ruminant theileriosis and its economical impact in Turkey. Turkiye Parazitol Derg. 2009;33(4):273-9.

35. Inci A, Nalbantoglu S, Cam Y, Atasever A, Karaer Z, Cakmak A, et al. Theilerioisis and tick infestations in sheep and goats around Kayseri. Turk $J$ Vet Anim Sci. 2003;27(1):57-60.

36. Uilenberg G. General review of tick-borne diseases of sheep and goats world-wide. Parassitologia. 1997;39(2):161-5.

37. Aktas M, Altay K, Dumanli N. PCR-based detection of Theileria ovis in Rhipicephalus bursa adult ticks. Vet Parasitol. 2006;140(3-4):259-63.

38. Tonbak S, Aktas M, Altay K, Azkur AK, Kalkan A, Bolat Y, et al. CrimeanCongo hemorrhagic fever virus: genetic analysis and tick survey in Turkey. J Clin Microbiol. 2006:44(11):4120-4.

39. Altay K, Aktas M, Dumanli N, Aydin MF. Evaluation of a PCR and comparison with RLB for detection and differentiation of Theileria sp MK and other Theileria and Babesia species of small ruminants. Parasitol Res. 2008;103(2):319-23.

40. Schnittger $L$, Hong $Y$, Jianxun L, Ludwig W, Shayan $P$, Rahbari $S$, et al. Phylogenetic analysis by rRNA comparison of the highly pathogenic sheepinfecting parasites Theileria lestoquardi and a Theileria species identified in China. Ann N Y Acad Sci. 2000;916:271-5.

41. Phipps LP, Hernandez-Triana LM, Goharriz H, Welchman D, Johnson N. Detection of Theileria luwenshuni in sheep from Great Britain. Parasit Vectors. 2016;9(1):203.

42. Gholami S, Laktarashi B, Shiadeh MM, Spotin A. Genetic variability, phylogenetic evaluation and first global report of Theileria luwenshuni, T. buffeli, and T. ovis in sheepdogs in Iran. Parasitol Res. 2016;115(5):2125-30.

43. Yin H, Luo J. Ticks of small ruminants in China. Parasitol Res. 2007;101 Suppl 2:S187-9.

44. Bursali A, Keskin A, Tekin S. A review of the ticks (Acari: Ixodida) of Turkey: species diversity, hosts and geographical distribution. Exp Appl Acarol. 2012;57(1):91-104.

45. Razmi G, Pourhosseini M, Yaghfouri S, Rashidi A, Seidabadi M. Molecular detection of Theileria spp. and Babesia spp. in sheep and ixodid ticks from the northeast of Iran. J Parasitol. 2013;99(1):77-81.

46. Sevinc F, Sevinc M, Ekici OD, Yildiz R, Isik N, Aydogdu U. Babesia ovis infections: detailed clinical and laboratory observations in the pre- and posttreatment periods of 97 field cases. Vet Parasitol. 2013;191(1-2):35-43.

47. Orkun $\mathrm{O}$, Karaer Z, Cakmak A, Nalbantoglu S. Identification of tick-borne pathogens in ticks feeding on humans in Turkey. PLoS Negl Trop Dis. 2014;8(8):e3067.

48. Hornok S, Takacs N, Kontschan J, Gyorgy Z, Micsutka A, Iceton S, et al. Diversity of Haemaphysalis-associated piroplasms of ruminants in CentralEastern Europe, Hungary. Parasit Vectors. 2015;8:627.

49. Uilenberg G, Andreasen MP. Haematoxenus seperatus sp. n. (Sporozoa, Theileriidae), a new blood parasite of domestic sheep in Tanazania. In: Noval RAI, Perry BD, Young AS, editors. The Epidemiology of Theileriosis in Africa. London: Academic Press inc; 1992. p. 83.

50. Uilenberg GS, Schreuder BE. Studies on Theileriidae (Sporozoa) in Tanzania. Tick transmission of Haematoxenus veliferus. In: Noval RAl, Perry BD Young AS, editors. The Epidemiology of Theileriosis in Africa. London: Academic Press Inc; 1992. p. 83.

51. Sayin F, Dincer S, Karaer Z, Cakmak A, Yukary BA, Eren H, et al. Status of the tick-borne diseases in sheep and goats in Turkey. Parassitologia. 1997;39:153-6. 
52. Torina A, Vicente J, Alongi A, Scimeca S, Turla R, Nicosia S, et al. Observed prevalence of tick-borne pathogens in domestic animals in Sicily, Italy during 2003-2005. Zoonoses Public Health. 2007;54:8-15.

53. de la Fuente J, Atkinson MW, Naranjo V, Fernandez de Mera IG, Mangold AJ, Keating KA, Kocan KM. Sequence analysis of the msp4 gene of Anaplasma ovis strains. Vet Microbiol. 2007;119(2-4):375-81.

54. Chochlakis D, loannou I, Sharif L, Kokkini S, Hristophi N, Dimitriou T, et al. Prevalence of Anaplasma sp. in goats and sheep in Cyprus. Vector Borne Zoonotic Dis. 2009;9:457-63.

55. Torina A, Galindo RC, Vicente J, Di Marco V, Russo M, Aronica V, Fiasconaro M, Scimeca S, Alongi A, Caracappa S, et al. Characterization of Anaplasma phagocytophilum and A. ovis infection in a naturally infected sheep flock with poor health condition. Trop Anim Health Prod. 2010;42(7):1327-31.

56. Derdakova M, Stefancikova A, Spitalska E, Taragelova V, Kostalova T, Hrklova $\mathrm{G}$, et al. Emergence and genetic variability of Anaplasma species in small ruminants and ticks from Central Europe. Vet Microbiol. 2011;153:293-8.

57. Tibbitts T, Goff W, Foreyt W, Stiller D. Susceptibility of two Rocky Mountain bighorn sheep to experimental infection with Anaplasma ovis. J Wild Dis. 1992;28(1):125-9.

58. Ndung'u LW, Aguirre C, Rurangirwa FR, McElwain TF, McGuire TC, Knowles DP, et al. Detection of Anaplasma ovis infection in goats by major surface protein 5 competitive inhibition enzyme-linked immunosorbent assay. J Clin Microbiol. 1995;33(3):675-9.

59. Friedhoff KT. Tick-borne diseases of sheep and goats caused by Babesia, Theileria or Anaplasma spp. Parassitologia. 1997;39(2):99-109.

60. Stuen S. Anaplasma phagocytophilum - the most widespread tick-borne infection in animals in Europe. Vet Res Commun. 2007;31 Suppl 1:79-84.

61. Razzaq F, Khosa T, Ahmad S, Hussain M, Saeed Z, Khan MA, et al. Prevalence of Anaplasma phagocytophilum in horses from Southern Punjab (Pakistan). Trop Biomed. 2015;32:233-9.

62. Ben Said M, Belkahia H, Alberti A, Zobba R, Bousrih M, Yahiaoui M, et al. Molecular survey of Anaplasma species in small ruminants reveals the presence of novel strains closely related to A. phagocytophilum in Tunisia. Vector Borne Zoonotic Dis. 2015;15(10):580-90

63. Kocan KM, Busby AT, Allison RW, Breshears MA, Coburn L, Galindo RC, et al. Sheep experimentally infected with a human isolate of Anaplasma phagocytophilum serve as a host for infection of Ixodes scapularis ticks. Ticks Tick Borne Dis. 2012;3:147-53.

64. Anderson $\mathrm{K}$, Ezenwa VO, Jolles AE. Tick infestation patterns in free ranging African buffalo (Syncercus caffer): effects of host innate immunity and niche segregation among tick species. Int J Parasitol Parasites Wild. 2013;2:1-9.

65. Bakheit MA, Latif AA. The innate resistance of Kenana cattle to tropical theileriosis (Theileria annulata infection) in the Sudan. Ann N Y Acad Sci. 2002:969:159-63.

66. Simuunza M, Weir W, Courcier E, Tait A, Shiels B. Epidemiological analysis of tick-borne diseases in Zambia. Vet Parasitol. 2011:175:331-42.

67. Stuen S, Engvall EO. Artursson K Persistence of Ehrlichia phagocytophila infection in lambs in relation to clinical parameters and antibody responses. Vet Rec. 1998;143:553-5.

68. Niu QL, Luo JX, Guan GQ, Ma ML, Liu ZJ, Liu AH, et al. Detection and differentiation of ovine Theileria and Babesia by reverse line blotting in China. Parasitol Res. 2009;104(6):1417-23.

69. Santos M, Soares R, Costa P, Amaro A, Inacio J, Gomes J. Revisiting the Tams1-encoding gene as a species-specific target for the molecular detection of Theileria annulata in bovine blood samples. Ticks Tick-Borne Dis. 2013;4:72-7.

70. Gomes J, Soares R, Santos M, Santos-Gomes G, Botelho A, Amaro A, et al. Detection of Theileria and Babesia infections amongst asymptomatic cattle in Portugal. Ticks Tick-Borne Dis. 2013:4:148-51.

71. Edwards MC, Gibbs RA. Multiplex PCR - Advantages, development, and applications. PCR Meth Appl. 1994:3:S65-75.

72. Henegariu O, Heerema NA, Dlouhy SR, Vance GH, Vogt PH. Multiplex PCR: critical parameters and step-by-step protocol. Biotechniques. 1997;23:504-11.

73. Martins TM, Pedro OC, Caldeira RA, do Rosario VE, Neves L, Domingos A. Detection of bovine babesiosis in Mozambique by a novel seminested hotstart PCR method. Vet Parasitol. 2008;153:225-30.

\section{Submit your next manuscript to BioMed Central and we will help you at every step:}

- We accept pre-submission inquiries

- Our selector tool helps you to find the most relevant journal

- We provide round the clock customer support

- Convenient online submission

- Thorough peer review

- Inclusion in PubMed and all major indexing services

- Maximum visibility for your research

Submit your manuscript at www.biomedcentral.com/submit
Biomed Central 